\title{
Genomic Approaches to Unveil the Physiological Pathways Activated in Arabidopsis Treated with Plant-Derived Raw Extracts
}

\author{
A. Santaniello ${ }^{1}$, F.M. Giorgi ${ }^{2,3}$, D. Di Tommaso ${ }^{4}$, G. Di Tommaso ${ }^{4}$, \\ A. Piaggesi ${ }^{4}$ and P. Perata \\ ${ }^{1}$ PlantLab, Scuola Superiore Sant'Anna, Piazza Martiri della Liberta 33, Pisa, 56127, \\ Italy \\ 2 Istituto di Genomica Applicata, via Linussio 51, Udine, 33100, Italy \\ ${ }^{3}$ Dipartimento di Scienze Agrarie ed Ambientali, Università di Udine, via delle Scienze \\ 206, Udine, 33100, Italy \\ ${ }^{4}$ Valagro SpA, via Cagliari 1, Atessa (CH), 66041, Italy
}

Keywords: biostimulants, microarrays, ABA

\begin{abstract}
DNA microarrays can be used to obtain a fingerprint of the transcriptional status of the plant or cell under a given condition and may be useful for characterising which genes respond, either by induction or repression, to novel stimuli or specific treatments. An in-depth bioinformatical analysis of all the data produced by microarrays can further highlight the metabolic or functional pathways most affected by the treatment. This approach has been used to investigate the effects induced by the treatment of different plant-derived raw materials, provided by Valagro SpA, on Arabidopsis seedlings. A clear example is represented by treatment with a raw plant-derived protein extract (VAL-P01). In this case the treatment induced genes related to $\mathrm{ABA}$ and osmotic stress treatment. We therefore demonstrated that VAL-P01 was able to mimic in planta the same pattern of responses linked to ABA treatment or osmotic stress, making the plant stronger against possible further stresses. Another plant extract, VAL-P02, was shown to be significantly altering the transcription of senescence genes, making it an ideal candidate adjuvant for the prolonged shelf-life of vegetal products.
\end{abstract}

\section{INTRODUCTION}

Natural products in agriculture can limit the use of environmentally harmful chemical inputs used for increasing crop yield and promote plant development, growth and nutrients uptake. Recently, a class of natural products for agricultural applications is attracting the interest of the market and the research community: the biostimulants. As defined in Khan et al. (2009), biostimulants correspond to "materials, other than fertilizers, that promote plant growth when they are applied in small quantities". A more recent definition better explains the characteristics of these products: "plant biostimulants are substances and materials, with the exception of nutrients and pesticide, which when applied to plants, seeds or growing substrate in specific formulations, have the capacity to modify physiological processes of plants in a way that provides potential benefits to growth, development and/or stress response" (Du Jardin, 2012). According to the above reported definition, the application of biostimulants has a positive impact on plant nutrition and plant growth, while at the same time providing anti-stress effects (Richardson et al., 2004). Biostimulant formulas are proprietary but most of them contain similar components: plant hormone-like compounds, amino acids, humic acids, manure and/or sea kelp extracts (Maini, 2006; Vinković et al., 2007; Mora et al., 2010).

Several reports highlight the beneficial physiological effects induced by the crop treatment with biostimulants, but the molecular mechanisms behind these effects are still unknown (Vernieri et al., 2006). Gene expression determines the plant's phenotype, physiology and response to the environment. Therefore, analysis of gene expression can provide clues about regulatory mechanisms, biochemical pathways and broader cellular functions that are affected by biostimulants. Nowadays, DNA microarrays represent a high-throughput technology to rapidly and quantitatively measure the parallel expression 
of thousands of genes (Aharoni and Vorst, 2002). Transcript profiling provided by microarray datasets can generate a picture of cellular functions under a given experimental condition (Schena et al., 1995; Tan et al., 2009).

Here, we present a microarray-based gene expression study aimed at elucidating the molecular mechanisms ignited by several crude plant extracts, acting as biostimulants. We measure the effect of these compounds on a well-studied model plant, Arabidopsis thaliana (Lamesch et al., 2012), by using the Affymetrix ATH1 GeneChip microarray, which is able to detect the expression of more than two-thirds $(21,377$ out of 27,416) of the Arabidopsis thaliana genes (Giorgi et al., 2013). A subsequent bioinformatical analysis is applied on the results to investigate which are the physiological pathways most affected by the biostimulants.

\section{MATERIAL AND METHODS}

\section{Plant Material and Growth Conditions}

Arabidopsis (Arabidopsis thaliana) ecotype Columbia-0 was used in this study. Arabidopsis seedlings plates have been prepared as described in Banti et al. (2010). The samples have been harvested 4, 12 and 24 hours after the treatments with the biostimulants. For the treatments we used eight plant crude extract (VAL-P01 to VALP08) with different natural origin. Including a two-replicates control plants panel, this sums up to 30 samples, plus two plant controls harvested before the treatment. For drought stress experiments, Arabidopsis adult plants were grown in a climatic cell, with controlled conditions $\left(\mathrm{T}=23^{\circ} \mathrm{C}, 14-/ 10-\mathrm{h}\right.$ photoperiod at $150 \mathrm{mmol}$ photons $\left.\mathrm{m}^{-2} \mathrm{~s}^{-1}\right)$ and stress was induced by stopping watering for 10 days.

\section{RNA Isolation, cRNA Synthesis, and Hybridization to Affymetrix GeneChips}

Total RNA was extracted from the seedling samples, using the Ambion RNAqueous extraction kit (Ambion). RNA quality was assessed by agarose gel electrophoresis and spectrophotometry. RNA was processed for use on Affymetrix Arabidopsis ATH1 GeneChip arrays (Affymetrix, Santa Clara, CA), according to the manufacturer's protocol. In brief, $10 \mu \mathrm{g}$ of total RNA was used in a reverse transcription reaction (Ambion MessageAmp kit) to generate first-strand cDNA. After second-strand synthesis, double-strand cDNA was used in an in vitro transcription reaction to generate biotinylated cRNA. After purification and fragmentation, biotinylated cRNA was used for hybridization. This generated 32 raw probe intensity numerical matrices, stored as cell intensity (CEL) files.

\section{Microarray Data Analysis}

Raw microarray signal intensities for each of the 32 measured samples were loaded as CEL files into the R environment (Ihaka and Gentleman, 1996) via the affy package (Gautier et al., 2004). The probe signals were background-corrected following the RMA procedure (Wu et al., 2004), then all samples were quantile-normalized and the probes were finally summarized into unlogged single gene values via the median polish procedure (Giorgi et al., 2010) using the standard probeset-to-gene map (CDF) provided by Affymetrix. All data passed all default quality tests assessed by the Robin pipeline for Affymetrix microarrays (Lohse et al., 2010).

Genes were flagged as "differentially expressed" in each treated vs. control contrast if (i) change is significant $(\mathrm{P} \leq 0.05)$ as defined by the PUMA pipeline with default parameters (Pearson et al., 2009) (ii) second, the absolute $\log _{2}$ fold change must be higher than $2\left(\log _{2} \mathrm{FC}\right.$, logarithm of the ratio between the treated signal divided by the control signal $\log _{2} \mathrm{FC} \geq 2$ ("induced") $\log _{2} \mathrm{FC} \leq 2$ ("repressed").

UPGMA-like hierarchical clustering of the samples was performed using the $\mathrm{R}$ package pvclust (Suzuki and Shimodaira, 2006), applying the average method after calculating the distance matrix between samples as 1-PCC (Pearson Correlation Coefficient). 100 bootstrap values were generated and reported in each node of the tree as 
BP (bootstrap probability).

Ontological assignment of each gene to a particular molecular pathway or biological function was done using the Mapman annotation (Usadel et al., 2005). Overrepresentation analyses of particular functions/pathways within lists of genes were performed on the MEFISTO tool (http://www.usadellab.org/cms/index.php?page $=$ mefisto). Visual representation of transcriptional induction/repression per pathway was obtained via the Mapman software (Usadel et al., 2005). Similarities between the expression profiles generated in this study and other GeneChip-based publicly available data were investigated; this was obtained via two independent cross-experiment comparative approaches: FARO http://www.cbs.dtu.dk/services/faro/ (Manijak and Nielsen, 2011) and AtCAST v2.0.6 http://atpbsmd.yokohama-cu.ac.jp/cgi/network/ home.cgi (Sasaki et al., 2011).

\section{RESULTS}

Arabidopsis seedlings were treated with eight different biostimulants (Table 1). A time-course experiment was performed to identify responses that are time-dependent. The microarray analysis demonstrates that Arabidopsis plants respond to each treatment by changes in gene expression at all three time points analysed. To find similarities among the different treatments we performed an unsupervised hierarchical clustering of the gene expression profiles from all the samples. This yielded a tree with distinct subclusters (Fig. 1). A first distinct branch groups together all samples treated with VAL-P02; a second branch groups together all VAL-P07 and two out of three VAL-P01 treatments. The rest of the samples are grouped together with the respective time controls, indicating that, for these samples, diurnal changes have a stronger effect than the treatment itself, with respect to general transcriptional state.

We decided, therefore, to deepen our analysis on the more peculiar classes of response, specifically focusing on VAL-P01 and VAL-P02, which clustered separately (Fig. 1) and which markedly change gene expression compared to other treatments with the exception of VAL-P07 (Fig. 2), which clustered with VAL-P01. We found that VALP01 induced 99 genes $4 \mathrm{~h}$ after the treatment, 110 genes after $12 \mathrm{~h}$ and 85 genes after $24 \mathrm{~h}$. The repressed genes were 58 after $4 \mathrm{~h}, 59$ after $12 \mathrm{~h}$, and 41 after $24 \mathrm{~h}$ from the treatment. VAL-P02 induced genes were 343 genes after $4 \mathrm{~h}, 375$ genes after $12 \mathrm{~h}$ and 415 genes after $24 \mathrm{~h}$ from the treatment. The VAL-P02 down regulated genes were 115 after $4 \mathrm{~h}, 493$ after $12 \mathrm{~h}$, and 235 after $24 \mathrm{~h}$ (Fig. 2). Amongst the biostimulants used, VAL-P02 has the stronger effects in terms of transcriptional changes in comparison to the control samples (Fig. 2).

In order to obtain a global picture of the effects of the treatments on biological processes, all transcriptional changes were analysed using the MapMan software (Fig. 3). This analysis highlighted the most interesting biological processes affected by VAL-P01 and VAL-P02.

Significantly induced Mapman classes of genes (i.e., over-represented biological pathways or functions) are indicated for VAL-P01 in Table 2 and for VAL-P02 in Table 3 at three time points after treatment. VAL-P01 exerted a clear effect on ABA signalling and influenced anthocyanin synthesis. At2g47770 (TSPO-related) was the most induced one and it is mainly expressed in dry seeds, after osmotic and salt stress or by the application of abscisic acid (ABA) (Guillaumot et al., 2009). At5g59220 (SAG113) belongs to the group of $\mathrm{ABA}$ signalling genes associated to water loss during leaf senescence (Zhang et al., 2012). ABA responsive elements-binding factors are highly induced by the treatment with VAL-P01, namely At4g34000 (ABF3), At3g19290 (ABF4), At3g56850 (AREB3), At3g19290 (AREB2), all considered as key transcriptional regulators of ABA pathway (Choi et al., 2005; Finkelstein et al., 2005). Other ABA signalling genes are also present in the VAL-P01-induced list: At4g26080 (ABI1), At5g57050 (ABI2), At3g24650 (ABI3) and At3g08550 (ABI8) (Merlot et al., 2001; Brady et al., 2003; Brocard-Gifford et al., 2004). Another stress gene, whose expression is enhanced by VAL-P01is At5g15960 (KIN1), is a well-known responder to cold- and drought-stress 
(Izawa et al., 1993).

VAL-P01 also induces several anthocyanin pathway genes, principally At $1 g 56650$ (PAP1, Production of Anthocyanin Pigment 1), a key transcription factor for anthocyanins biosynthesis (Tohge et al., 2005) and At5g42800 (DFR, DihydroFlavonol 4-Reductase) (Harborne and Williams, 2000; Winkel-Shirley, 2001). Other flavonoid synthesis pathways are induced by VAL-P01, for example we found two chalcone/stilbene synthases (At4g00040 and Atlg02050) and flavonol synthases At5g63580 (FLS2) and At5g63590 (FLS3). Furthermore, the nucleotide sugar metabolism, responsible for synthesizing, for example, pectin precursors, is deeply affected by the VAL-P01 biostimulant (specifically, four UDP-glycosyl transferases are significantly induced: At1g01390, At5g49690, At2g18560 and At5g65550).

Concerning the genes responding to VAL-P02 we noticed the strong induction of genes belonging the DIN family (Dark INducible genes): At3g60140 (DIN2), At3g49620 (DIN11), At4g35770 (DIN1), At3g13450 (DIN4), At3g47340 (DIN6), At3g06850 (DIN3), Atlg67070 (DIN9), At5g20250 (DIN10) and At3g06850 (DIN3). DIN genes are typically induced under dark condition and sugar starvation (Trethewey and Rees, 1994), but also accumulate during natural leaf senescence (Fujiki et al., 2000; Fujiki et al., 2008).

We further proceeded investigating how the transcriptional responses to biostimulants VAL-P01 and VAL-P02 could mimic classical plant treatments available in Arabidopsis microarray database with the AtCAST pipeline (Sasaki et al., 2011). The AtCAST results were confirmed by the FARO server, whose purpose is also to find expression pattern similarities across microarray experiments (Manijak and Nielsen, 2011). The experiments that were found to be significantly similar to our treatments are listed in Table 4, connected in a network view displayed in Figure 4, showing genes are transcriptionally responding in a similar way. The pattern of gene expression for VALP02 correlates with that of both abiotic stress (particularly osmotic) and biotic stress (such as that induced by the bacterial extracts HrpZ or flagellin, or by living pathogens). The pattern of gene expression for VAL-P01 is strictly related with the microarray datasets from experiments related to $\mathrm{ABA}$ treatments, plus various abiotic stresses at least partly involving ABA signalling pathways.

In order to validate the hints given by the general pathway analysis for VAL-P01, and in particular the prediction that ABA-related stress tolerance mechanisms are highly activated by this biostimulant, we performed a tolerance drought stress. Arabidopsis adult plants were deprived of water for 10 days and, remarkably, plants that were previously treated with VAL-P01 could better tolerate the stress (Fig. 5). These results demonstrate that VAL-P01 is able to mimic the ABA induced-effects, not only at the transcriptional, but also at the physiological level.

\section{DISCUSSION}

In this work we demonstrated that microarrays constitute a powerful tool to characterize the effect of natural, raw substances predicting their possible use as biostimulants. The analyses of our microarray data and the further functional analyses, using the MapMan and AtCAST softwares, allowed us to link gene expression changes induced by the treatments with physiological processes. Our results not only validate the proposed method, but also provide new data on not-yet characterized raw materials that can be used to rapidly develop new biostimulants.

The results obtained in the drought-tolerance experiments are in agreement with the microarray data highlighting an effect of VAL-P01 on ABA and abiotic-stress related genes. Abscisic acid activates genes associated with different processes in plant such as storage proteins, dormancy, germination, the arrest of embryonic development, leaves senescence and the closure of stomata (Sreenivasulu et al., 2006, 2010). Different stress conditions such as low temperatures, drought, salinity, heat, wounding, desiccation, drought, cold and light result in increased levels of $\mathrm{ABA}$, which is considered as a plant stress hormone (Hauser et al., 2011). Several studies have indeed demonstrated a pivotal role for $\mathrm{ABA}$ in the modulation, at the gene level, of adaptive responses for plants in 
adverse environmental conditions (Cutler et al., 2010; Fujita et al., 2011). ABA is produced under drought and low temperature stresses and increased ABA content in leaves was observed during hardening, cold acclimation and salt stress in several crops such as winter wheat, potatoes, and alfalfa (Lalk and Dörffling, 1985; Luo et al., 1992). A number of genes have been described that respond to drought and low temperature stress at the transcription level (Thomashow, 1998), and it was demonstrated that their regulation is related to $\mathrm{ABA}$ as a mediator in triggering plant responses to adverse environmental stimuli (Zeevaart and Creelman, 1988). For cold stress acclimation the key role of ABA production is also well documented (Yamaguchi-Shinozaki and Shinozaki, 2005), and the role of ABA in drought tolerance has been extensively studied in Arabidopsis (Bray, 1997). Our results show that VAL-P01 activates genes related to ABA response and also induces tolerance to drought stress further support the link between ABA and drought stress. VAL-P01 can represent an ingredient to develop a new biostimulant to protect plants against a series of stresses that are linked to ABA as a signalling molecule. We observed that VAL-P02 induces a specific class of genes, which are involved in the senescence process in plant, namely the DIN genes. DIN transcripts also accumulate during natural leaf senescence (Fujiki et al., 2008), and their expression in darkness seems to be triggered, at least in part, by sugar starvation, which often prevails in plants within several hours after darkness (Trethewey and Rees, 1994). This observation sustains the idea that the VAL-P02 might affect the senescence process in treated plants. VAL-P02 could therefore be used to prolong the shelf-life of horticultural products, but further experimental evidence is required to support this proposal.

\section{ACKNOWLEDGEMENTS}

The present work was possible thanks to the support by Valagro SpA.

\section{Literature Cited}

Aharoni, A. and Vorst, O. 2002. DNA microarrays for functional plant genomics. Plant Molecular Biology 48:99-118.

Banti, V., Mafessoni, F. et al. 2010. The heat-inducible transcription factor HsfA2 enhances anoxia tolerance in Arabidopsis. Plant Physiol. 152(3):1471-83.

Brady, S.M., Sarkar, S.F., Bonetta, D. and McCourt, P. 2003. The ABSCISIC ACID INSENSITIVE 3 (ABI3) gene is modulated by farnesylation and is involved in auxin signaling and lateral root development in Arabidopsis. The Plant Journal 34:67-75.

Bray, E.A. 1997. Plant responses to water deficit. Trends in Plant Science 2:48-54.

Brocard-Gifford, I., Lynch, T.J., Garcia, M.E., Malhotra, B. and Finkelstein, R.R. 2004. The Arabidopsis thaliana ABSCISIC ACID-INSENSITIVE8 locus encodes a novel protein mediating abscisic acid and sugar responses essential for growth. The Plant Cell Online 16:406-421.

Choi, H., Park, H.J., Park, J.H., Kim, S., Im, M.Y., Seo, H.H. and Kim, S.Y. 2005. Arabidopsis calcium-dependent protein kinase AtCPK32 interacts with ABF4, a transcriptional regulator of abscisic acid-responsive gene expression, and modulates its activity. Plant Physiology 139:1750-1761.

Cutler, S.R., Rodriguez, P.L., Finkelstein, R.R. and Abrams, S.R. 2010. Abscisic acid: emergence of a core signaling network. Annual Reviews Plant Biology 61:651-679.

Du Jardin, P. 2012. The Science of Plant Biostimulants - A BAbliographic analysis, European Commission Report - Contract 30-CE0455515/00-96, "Ad hoc study on bio-stimulants products".

Finkelstein, R.R. and Rock, C.D. 2002. Abscisic Acid Biosynthesis and Response, The Arabidopsis Book/American Society of Plant Biologists, 1 .

Fujiki, Y., Yoshikawa, Y., Sato, T., Inada, N., Ito, M., Nishida, I. and Watanabe, A. 2008. Dark-inducible genes from Arabidopsis thaliana are associated with leaf senescence and repressed by sugars. Physiologia Plantarum 111:345-352.

Fujita, Y., Fujita, M., Shinozaki, K. and Yamaguchi-Shinozaki, K. 2011. ABA-mediated transcriptional regulation in response to osmotic stress in plants. Journal of Plant 
Research 124:509-525.

Gautier, L., Cope, L., Bolstad, B.M. and Irizarry, R.A. 2004. Affy-analysis of Affymetrix GeneChip data at the probe level. Bioinformatics 20:307-315.

Giorgi, F.M., Bolger, A., Lohse, M. and Usadel, B. 2010. Algorithm-driven artifacts in median polish summarization of microarray data. BMC Bioinformatics 11:553.

Giorgi, F.M., Del Fabbro, C. and Licausi, F. 2013. Comparative study of RNA-seq- and microarray-derived coexpression networks in Arabidopsis thaliana. Bioinformatics, Advance Access, doi: 10.1093/bioinformatics/btt1053.

Guillaumot, D., Guillon, S., Morsomme, P. and Batoko, H. 2009. ABA, porphyrins and plant TSPO-related protein. Plant Signaling \& Behavior 4:1087-1090.

Harborne, J.B. and Williams, C.A. 2000. Advances in flavonoid research since 1992. Phytochemistry 55:481-504.

Hauser, F., Waadt, R. and Schroeder, J.I. 2011. Evolution of abscisic acid synthesis and signaling mechanisms. Current Biology 21:R346-R355.

Ihaka, R. and Gentleman, R. 1996. R: a language for data analysis and graphics. Journal of Computational and Graphical Statistics 5:299-314.

Izawa, T., Foster, R. and Chua, N.H. 1993. Plant bZIP protein DNA binding specificity. Journal of Molecular Biology 230:1131-1144.

Khan, W., Rayirath, U.P., Subramanian, S., Jithesh, M.N., Rayorath, P., Hodges, D.M. and Prithiviraj, B. 2009. Seaweed extracts as biostimulants of plant growth and development. Journal of Plant Growth Regulation 28:386-399.

Lalk, I. and Dörffling, K. 1985: Hardening, abscisic acid, proline and freezing resistance in two winter wheat varieties. Plant Physiol. 63:287-292.

Lamesch, P., Berardini, T.Z., Li, D., Swarbreck, D., Wilks, C., Sasidharan, R. and GarciaHernandez, M. 2012. The Arabidopsis Information Resource (TAIR): improved gene annotation and new tools. Nucleic Acids Research 40:D1202-D1210.

Lohse, M., Nunes-Nesi, A., Krüger, P., Nagel, A., Hannemann, J., Giorgi, F.M. and Selbig, J. 2010. Robin: an intuitive wizard application for R-based expression microarray quality assessment and analysis. Plant Physiol. 153:642-651.

Luo, M., Liu, J.H., Mohapatra, S., Hill, R.D. and Mohapatra, S.S. 1992. Characterization of a gene family encoding abscisic acid- and environmental stress-inducible proteins of alfalfa. J. Biol. Chem. 267:15367-15374.

Maini, P. 2006. The experience of the first biostimulant, based on aminoacids and peptides: a short retrospective review on the laboratory researches and the practical results. Fertilitas Agrorum 1:29-43.

Manijak, M.P. and Nielsen, H.B. 2011. FARO server: Meta-analysis of gene expression by matching gene expression signatures to a compendium of public gene expression data. BMC Research Notes 4:181.

Merlot, S., Gosti, F., Guerrier, D., Vavasseur, A. and Giraudat, J. 2001. The ABI1 and $\mathrm{ABI} 2$ protein phosphatases $2 \mathrm{C}$ act in a negative feedback regulatory loop of the abscisic acid signalling pathway. The Plant Journal 25:295-303.

Mora, V., Bacaicoa, E., Zamarreño, A.M., Aguirre, E., Garnica, M., Fuentes, M. and García-Mina, J.M. 2010. Action of humic acid on promotion of cucumber shoot growth involves nitrate-related changes associated with the root-to-shoot distribution of cytokinins, polyamines and mineral nutrients. Journal of Plant Physiology 167:633642.

Newman, T., de Bruijn, F.J., Green, P., Keegstra, K., Kende, H., McIntosh, L. and Thomashow, M. 1994. Genes galore: a summary of methods for accessing results from large-scale partial sequencing of anonymous Arabidopsis cDNA clones. Plant Physiol. 106:1241-1255.

Pearson, R., Liu, X., Sanguinetti, G., Milo, M., Lawrence, N. and Rattray, M. 2009. puma: a bioconductor package for propagating uncertainty in microarray analysis. BMC Bioinformatics 10:211.

Richardson, A., Aikens, M., Berlyn, G. and Marshall, P. 2004. Drought stress and paper birch (Betula papyrifera) seedlings: effects of an organic biostimulant on plant health 
and stress tolerance, and detection of stress effects with instrument-based, noninvasive methods. Journal of Arboriculture 30:52-61.

Sasaki, E., Takahashi, C., Asami, T. and Shimada, Y. 2011. AtCAST, a tool for exploring gene expression similarities among DNA microarray experiments using networks. Plant and Cell Physiology 52:169-180.

Schena, M., Shalon, D., Davis, R.W. and Brown, P.O. 1995. Quantitative monitoring of gene expression patterns with a complementary DNA microarray. Science 270:467470.

Shinozaki, K. and Yamaguchi-Shinozaki, K. 1996. Molecular responses to drought and cold stress. Current Opinion in Biotechnology 7:161-167.

Sreenivasulu, N., Radchuk, V., Alawady, A., Borisjuk, L., Weier, D., Staroske, N. and Usadel, B. 2010. Deregulation of abscisic acid contents causes abnormal endosperm development in the barley mutant seg8. The Plant Journal 64:589-603.

Sreenivasulu, N., Radchuk, V., Strickert, M., Miersch, O., Weschke, W. and Wobus, U. 2006. Gene expression patterns reveal tissue specific signaling networks controlling programmed cell death and ABA regulated maturation in developing barley seeds. The Plant Journal 47:310-327.

Suzuki, R. and Shimodaira, H. 2006. Pvclust: an R package for assessing the uncertainty in hierarchical clustering. Bioinformatics 22:1540-1542.

Tan, K., Ipcho, S., Trengove, R., Oliver, R. and Solomon, P. 2009. Assessing the impact of transcriptomics, proteomics and metabolomics on fungal phytopathology. Molecular Plant Pathology 10:703.

Thomashow, M.F. 1998. Role of cold-responsive genes in plant freezing tolerance. Plant Physiol. 118:1-8.

Tohge, T., Nishiyama, Y., Hirai, M.Y., Yano, M., Nakajima, J., Awazuhara, M. and Kitayama, M. 2005. Functional genomics by integrated analysis of metabolome and transcriptome of Arabidopsis plants over-expressing an MYB transcription factor. The Plant Journal 42:218-235.

Trethewey, R.N. and Rees, T. 1994. The role of the hexose transporter in the chloroplasts of Arabidopsis thaliana L. Planta 195:168-174.

Usadel, B., Nagel, A., Thimm, O., Redestig, H., Blaesing, O.E., Palacios-Rojas, N. and Steinhauser, D. 2005. Extension of the visualization tool MapMan to allow statistical analysis of arrays, display of coresponding genes, and comparison with known responses. Plant Physiol. 138:1195-1204.

Vernieri, P., Borghesi, E., Tognoni, F., Serra, G., Ferrante, A. and Piagessi, A. 2006. Use of biostimulants for reducing nutrient solution concentration in floating system. III International Symposium on Models for Plant Growth. Environmental Control and Farm Management in Protected Cultivation 718:477-484.

Vinković, T., Parađiković, N., Plavšić, H., Guberac, V. and Levai, L. 2007. Maize and soybean seed vigour under influence of seed age, seed treatment and temperature in cold stress test. Cereal Research Communications 35:1213-1216.

Winkel-Shirley, B. 2001. It takes a garden. How work on diverse plant species has contributed to an understanding of flavonoid metabolism. Plant Physiol. 127:13991404.

Wu, Z., Irizarry, R.A., Gentleman, R., Murillo, F.M. and Spencer, F. 2004. A model based background adjustment for oligonucleotide expression arrays. J. Amer. Stat. Assoc. 99:909-917.

Yamaguchi-Shinozaki, K. and Shinozaki, K. 1994. A novel cis-acting element in an Arabidopsis gene is involved in responsiveness to drought, low-temperature, or highsalt stress. The Plant Cell Online 6:251-264.

Yamaguchi-Shinozaki, K. and Shinozaki, K. 2005. Organization of cis-acting regulatory elements in osmotic-and cold-stress-responsive promoters. Trends in Plant Science 10:88-94.

Zeevaart, J. and Creelman, R. 1988. Metabolism and physiology of abscisic acid. Annual Review of Plant Physiology and Plant Molecular Biology 39:439-473. 


\section{$\underline{\text { Tables }}$}

Table 1. List and generic composition of biostimulant products experimented in the current study.

\begin{tabular}{lll}
\hline Code of raw material & Composition \\
\hline \multirow{2}{*}{ VAL-P01 } & $10 \%$ & total amino acids \\
& $6-10 \%$ & betaines \\
\hline & $2.8 \%$ & crude proteins \\
VAL-P02 & $14.5 \%$ & ashes \\
& $47 \%$ & total carbohydrates \\
& $72 \%$ & organic matter \\
\hline & $44 \%$ & total organic C \\
VAL-P03 & $75 \%$ & organic matter \\
& $47.6 \%$ & humic acids \\
& $12.1 \%$ & fulvic acids \\
\hline & $8 \%$ & crude proteins \\
VAL-P04 & $40-55 \%$ & ashes \\
& $9 \%$ & total amino acids \\
& $6 \%$ & sugar alcohols \\
& $35-45 \%$ & organic matter \\
\hline & $6 \%$ & crude proteins \\
& $40-55 \%$ & ashes \\
VAL-P05 & $3-4 \%$ & organic acids \\
& $4-6 \%$ & total amino acids \\
& $4 \%$ & sugar alcohols \\
& $1 \%$ & betaines \\
\hline & $40 \%$ & total organic C \\
VAL-P06 & $60 \%$ & organic matter \\
& $48 \%$ & wood derived polymer complex \\
\hline & $2-4 \%$ & crude proteins \\
& $12 \%$ & ashes \\
& $46-48 \%$ & total carbohydrates \\
& $30-40 \%$ & disaccharides \\
& $50-60 \%$ & organic matter \\
\hline & $25 \%$ & crude proteins \\
& $8.5 \%$ & ashes \\
& $11-12 \%$ & total amino acids \\
& $4-5 \%$ & free amino acids \\
& $13 \%$ & organic acids \\
& & organic matter \\
\hline & & \\
& & \\
& &
\end{tabular}


Table 2. List of the most induced functional groups affected by the treatment with VAL$\mathrm{P} 01$, at the three different time points. The mainly affected pathways were ABA signalling and flavonoids/anthocyanins synthesis (MEFISTO test, Fisher's Exact Test with Bonferroni correction, $\mathrm{P}$-value $<0.05$ ).

\begin{tabular}{lc}
\hline Induced gene group & $\begin{array}{c}\text { Over- } \\
\text { representation } \\
\text { corrected P-value }\end{array}$ \\
\hline Hormone metabolism - abscisic acid & \\
Secondary metabolism & $3.2319 \mathrm{E}-04$ \\
Secondary metabolism - flavonoids & $1.5126 \mathrm{E}-03$ \\
Hormone metabolism - abscisic acid.induced-regulated-responsive- & $3.1329 \mathrm{E}-03$ \\
activated & $7.2410 \mathrm{E}-03$ \\
Secondary metabolism - flavonoids.anthocyanins & $1.3072 \mathrm{E}-02$ \\
Development - late embryogenesis abundant & $1.9013 \mathrm{E}-02$ \\
Stress & $2.0278 \mathrm{E}-02$ \\
Miscellaneous - protease inhibitor/seed storage/lipid transfer protein (LTP) & $2.1421 \mathrm{E}-02$ \\
family protein & $2.8193 \mathrm{E}-02$ \\
Hormone metabolism & $4.7777 \mathrm{E}-02$ \\
Not assigned - unknown genes & \\
\hline \multicolumn{1}{c}{ Miscellaneous } & $1.4423 \mathrm{E}-07$ \\
Miscellaneous - protease inhibitor/seed storage/lipid transfer protein (LTP) & $2.9000 \mathrm{E}-06$ \\
family protein & $2.5290 \mathrm{E}-05$ \\
Hydroxyproline rich proteins & $4.2145 \mathrm{E}-04$ \\
Miscellaneous - cytochrome P450 & $1.7033 \mathrm{E}-03$ \\
Not assigned - unknown genes & $8.2087 \mathrm{E}-03$ \\
Hormone metabolism - abscisic acid.induced-regulated-responsive- & $1.0089 \mathrm{E}-02$ \\
activated & $1.1941 \mathrm{E}-02$ \\
\hline Hormone metabolism - abscisic acid & \\
Stress & $6.5378 \mathrm{E}-04$ \\
Hormone metabolism - abscisic acid & $1.0266 \mathrm{E}-03$ \\
Hormone metabolism - abscisic acid.induced-regulated-responsive- & $1.3140 \mathrm{E}-02$ \\
activated & $1.4001 \mathrm{E}-02$ \\
Not assigned - unknown genes & $4.9165 \mathrm{E}-02$ \\
\hline Hormone metabolism &
\end{tabular}


Table 3. List of the most induced functional groups affected by the treatment with VALP02, at the three different time points. The mainly affected pathways were stress signalling (MEFISTO test, Fisher's Exact Test with Bonferroni correction, $\mathrm{P}$-value $<0.05)$.

\begin{tabular}{|c|c|}
\hline Induced gene group & $\begin{array}{l}\text { Over-representation } \\
\text { corrected P-value }\end{array}$ \\
\hline \multicolumn{2}{|l|}{ VAL-P03 4 hours (343 genes) } \\
\hline Miscellaneous - glutathione S transferases & $5.4767 \mathrm{E}-12$ \\
\hline Stress & $1.4080 \mathrm{E}-06$ \\
\hline Stress - biotic & 4.8357E-04 \\
\hline Redox - glutaredoxins & $1.6900 \mathrm{E}-03$ \\
\hline $\begin{array}{l}\text { Miscellaneous - nitrilases, *nitrile lyases, berberine bridge enzymes, } \\
\text { reticuline oxidases, troponine reductases }\end{array}$ & $2.1198 \mathrm{E}-03$ \\
\hline Protein metabolism & $9.0506 \mathrm{E}-03$ \\
\hline Miscellaneous - cytochrome P450 & $9.2628 \mathrm{E}-03$ \\
\hline Amino acid metabolism - degradation - branched-chain group & $2.0613 \mathrm{E}-02$ \\
\hline Amino acid metabolism - degradation & $2.1886 \mathrm{E}-02$ \\
\hline Development & 4.0141E-02 \\
\hline Lipid metabolism - lipid degradation.lipases & $4.3466 \mathrm{E}-02$ \\
\hline \multicolumn{2}{|l|}{ VAL-P02 12 hours (375 genes) } \\
\hline Amino acid metabolism - degradation & $1.5639 \mathrm{E}-10$ \\
\hline Amino acid metabolism - degradation - branched-chain group & $1.1643 \mathrm{E}-06$ \\
\hline Miscellaneous - cytochrome P450 & $1.2009 \mathrm{E}-03$ \\
\hline Development & $2.7210 \mathrm{E}-03$ \\
\hline Redox - glutaredoxins & $3.3228 \mathrm{E}-03$ \\
\hline Amino acid metabolism - degradation - branched-chain group.leucine & 4.2222E-03 \\
\hline Minor CHO metabolism.trehalose.potential TPS/TPP & $3.5632 \mathrm{E}-02$ \\
\hline Secondary metabolism - flavonoids - anthocyanins & $1.1868 \mathrm{E}-02$ \\
\hline \multicolumn{2}{|l|}{ VAL-P02 24 hours (415 genes) } \\
\hline Hormone metabolism & $2.5360 \mathrm{E}-08$ \\
\hline Protein metabolism & $5.4674 \mathrm{E}-08$ \\
\hline Not assigned - unknown genes & $2.2613 \mathrm{E}-06$ \\
\hline Miscellaneous - glutathione S transferases & $6.9239 \mathrm{E}-06$ \\
\hline $\begin{array}{l}\text { RNA - regulation of transcription- WRKY domain transcription } \\
\text { factor family }\end{array}$ & 3.3093E-05 \\
\hline Miscellaneous - cytochrome P450 & $7.5490 \mathrm{E}-04$ \\
\hline DNA metabolism & $2.0105 \mathrm{E}-03$ \\
\hline Protein metabolism - degradation - ubiquitin & $8.5949 \mathrm{E}-03$ \\
\hline $\begin{array}{l}\text { Miscellaneous - nitrilases, *nitrile lyases, berberine bridge enzymes, } \\
\text { reticuline oxidases, troponine reductases }\end{array}$ & $9.1785 \mathrm{E}-03$ \\
\hline Development & 1.6316 \\
\hline Stress - biotic & $2.8210 \mathrm{E}-02$ \\
\hline
\end{tabular}


Table 4. List of the 10 experimental conditions most correlated to VAL-P01 or VAL-P02, sorted by absolute AtCAST-derived Spearman Correlation coefficient. The transcriptional similarities were assessed upon gene expression changes (all treatments vs. all controls) detected by the Arabidopsis microarray. Negative correlation values signify an opposite behaviour; positive correlation values signify a similar behaviour. Details are available on the AtCAST publication (Sasaki et al., 2011).

\begin{tabular}{|c|c|c|c|}
\hline Experiment & Genotype & Treatment/tissue & $\begin{array}{l}\text { Spearman } \\
\text { correlation }\end{array}$ \\
\hline \multicolumn{4}{|c|}{ VAL-P01 } \\
\hline ABA $1 \mathrm{~h}$ & Col-0 & $10 \mu \mathrm{M}$ ABA/seedling & 0.86 \\
\hline ABA $3 \mathrm{~h}$ & Col-0 & $10 \mu \mathrm{M} \mathrm{ABA} /$ seedling & 0.80 \\
\hline ARR22-ox (t-zeatin 3 h) & ARR22-ox & $20 \mu \mathrm{M} \mathrm{t}$-zeatin/seedling & -0.70 \\
\hline $\begin{array}{l}\text { Drought stress } 24 \mathrm{~h} \\
\text { (shoot) }\end{array}$ & Col-0 & $\begin{array}{l}\text { drought ( } 15 \text { min dry air then further } \\
\text { incubation in closed vessel)/shoots }\end{array}$ & 0.68 \\
\hline Prohexadione $12 \mathrm{~h}$ & Col-0 & $10 \mu \mathrm{M}$ prohexadione/seedling & 0.67 \\
\hline ABA $0.5 \mathrm{~h}$ & Col-0 & $10 \mu \mathrm{M}$ ABA/seedling & 0.65 \\
\hline Norflurazon & Col-0 & $5 \mu \mathrm{M}$ Norflurazon/seedling & -0.65 \\
\hline $\begin{array}{l}\text { Osmotic stress } 24 \mathrm{~h} \\
\text { (root) }\end{array}$ & Col-0 & osmotic stress (300 mM mannitol)/roots & 0.63 \\
\hline $\begin{array}{l}\text { Drought stress } 24 \mathrm{~h} \\
\text { (root) }\end{array}$ & Col-0 & $\begin{array}{l}\text { drought }(15 \mathrm{~min} \text { dry air then further } \\
\text { incubation in closed vessel }) / \text { roots } \\
\text { UV-B stress }\left(15 \mathrm{~min} 1.815 \mathrm{~min} 1.8 \mathrm{~W} / \mathrm{m}^{2}\right.\end{array}$ & 0.61 \\
\hline UV stress $24 \mathrm{~h}$ (shoot) & Col-0 & $\begin{array}{c}\text { Philips TL40W/12; thereafter } \\
\text { recovery/shoots }\end{array}$ & -0.60 \\
\hline \multicolumn{4}{|c|}{ VAL-P02 } \\
\hline $\mathrm{AgNO}_{3} 3 \mathrm{~h}$ & Col-0 & $10 \mu \mathrm{M} \mathrm{AgNO} /$ seedling & 0.84 \\
\hline Phytoprostane A1 $4 \mathrm{~h}$ & Col-2 & $75 \mu \mathrm{M}$ phytoprostane $\mathrm{A} 1 /$ seedling & 0.74 \\
\hline HairpinZ 4 h (leaf) & Col-0 & infiltrated with $10 \mu \mathrm{M} \mathrm{HrpZ/leaves}$ & 0.74 \\
\hline Phaseolicola 2 h (leaf) & Col-0 & $\begin{array}{l}\text { infiltrated with } 108 \mathrm{cfu} / \mathrm{ml} P \text {. syringae } \mathrm{pv} \text {. } \\
\text { phaseolicola harvested after } 2 \mathrm{~h} / \text { leaves }\end{array}$ & 0.73 \\
\hline P. infestans $6 \mathrm{~h}$ (leaf) & Col-0 & $P$. infestans $6 \mathrm{~h}$ (leaf)/leaves & 0.71 \\
\hline OPDA $4 \mathrm{~h}$ & Col-2 & $75 \mu \mathrm{M}$ OPDA/seedling & 0.70 \\
\hline Flagellin 4 h (leaf) & Col-0 & infiltrated with $1 \mu \mathrm{M}$ Flg22/leaves & 0.70 \\
\hline $\begin{array}{l}\text { Osmotic stress } 24 \mathrm{~h} \\
\text { (root) }\end{array}$ & Col-0 & osmotic stress (300 mM mannitol)/roots & 0.68 \\
\hline Salt stress $24 \mathrm{~h}$ (root) & Col-0 & salt stress $(150 \mathrm{mM} \mathrm{NaCl}) /$ roots & 0.64 \\
\hline $\begin{array}{l}\text { ARR22-ox (t-zeatin } \\
3 \mathrm{~h})\end{array}$ & ARR22-ox & $20 \mu \mathrm{M}$ t-zeatin/seedling & 0.55 \\
\hline
\end{tabular}




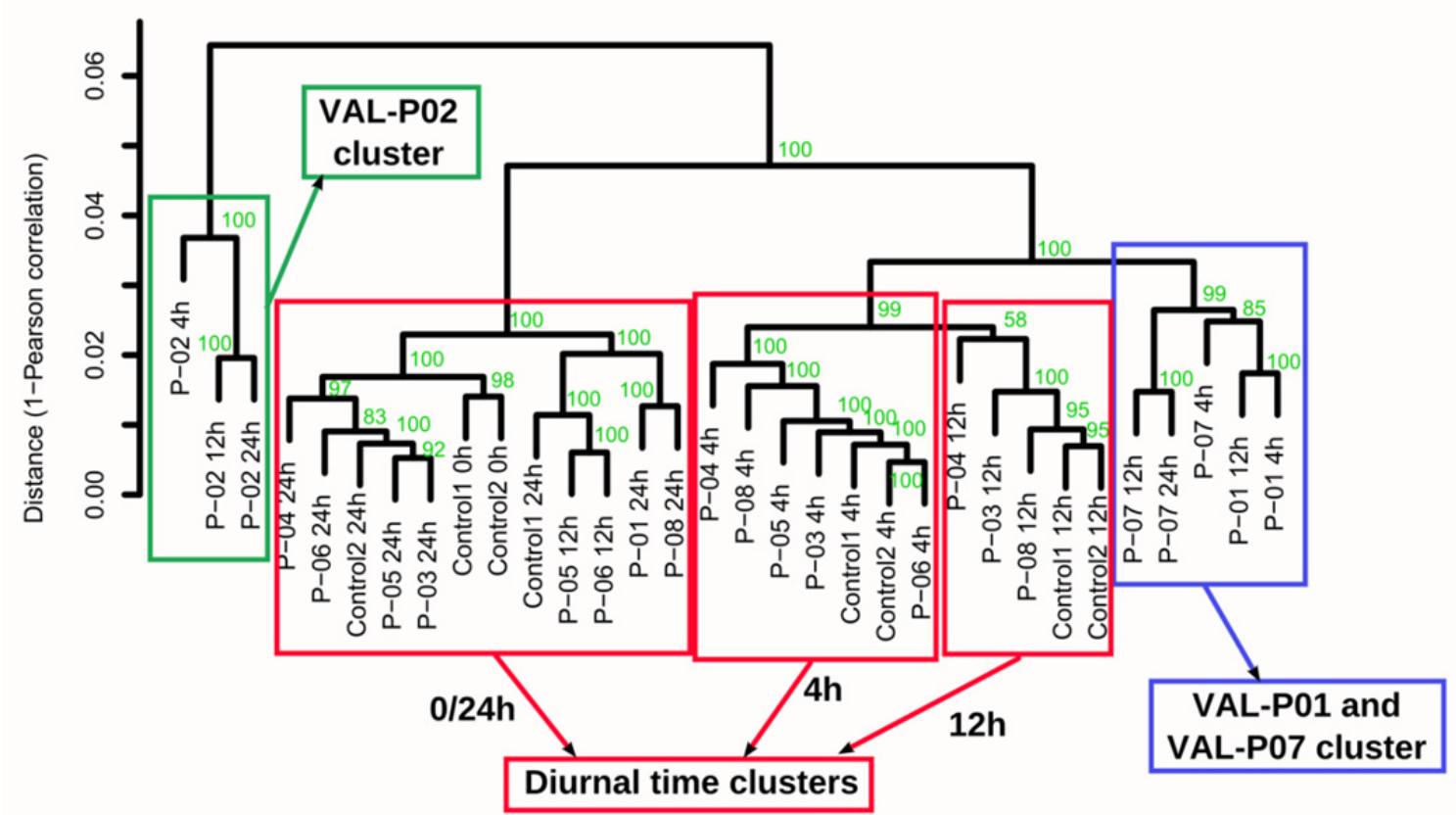

Fig. 1. UPGMA-like hierarchical clustering of the control and biostimulant-treated samples generated in this work. 100 bootstrap values were generated and reported in each node of the tree as BP (Bootstrap Probability). The tree was generated using the pvclust $\mathrm{R}$ package.

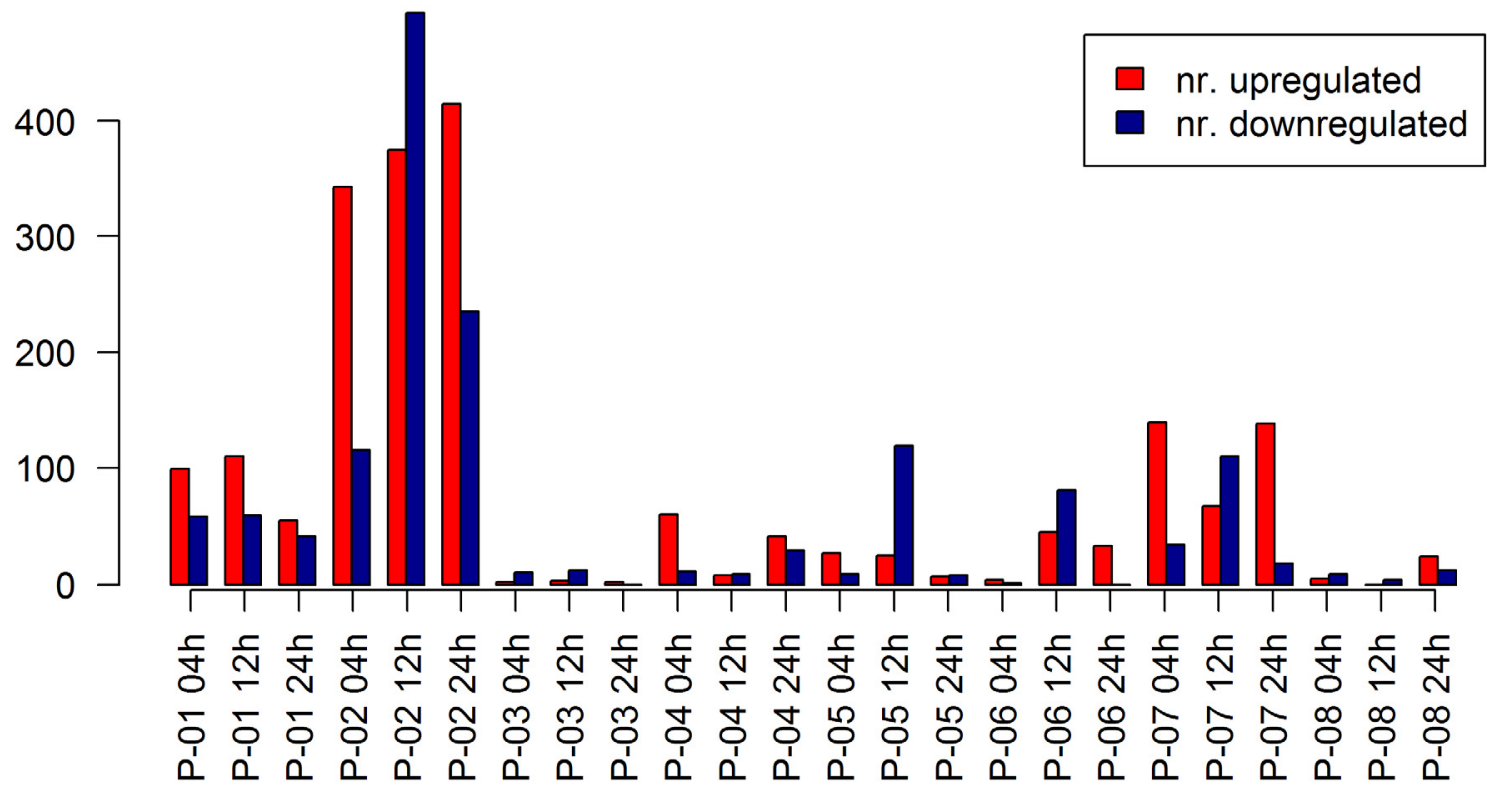

Fig. 2. Barplots indicating the number of significantly induced (red) and repressed (blue) genes for each treatment and each time point compared to control (untreated) plants. 


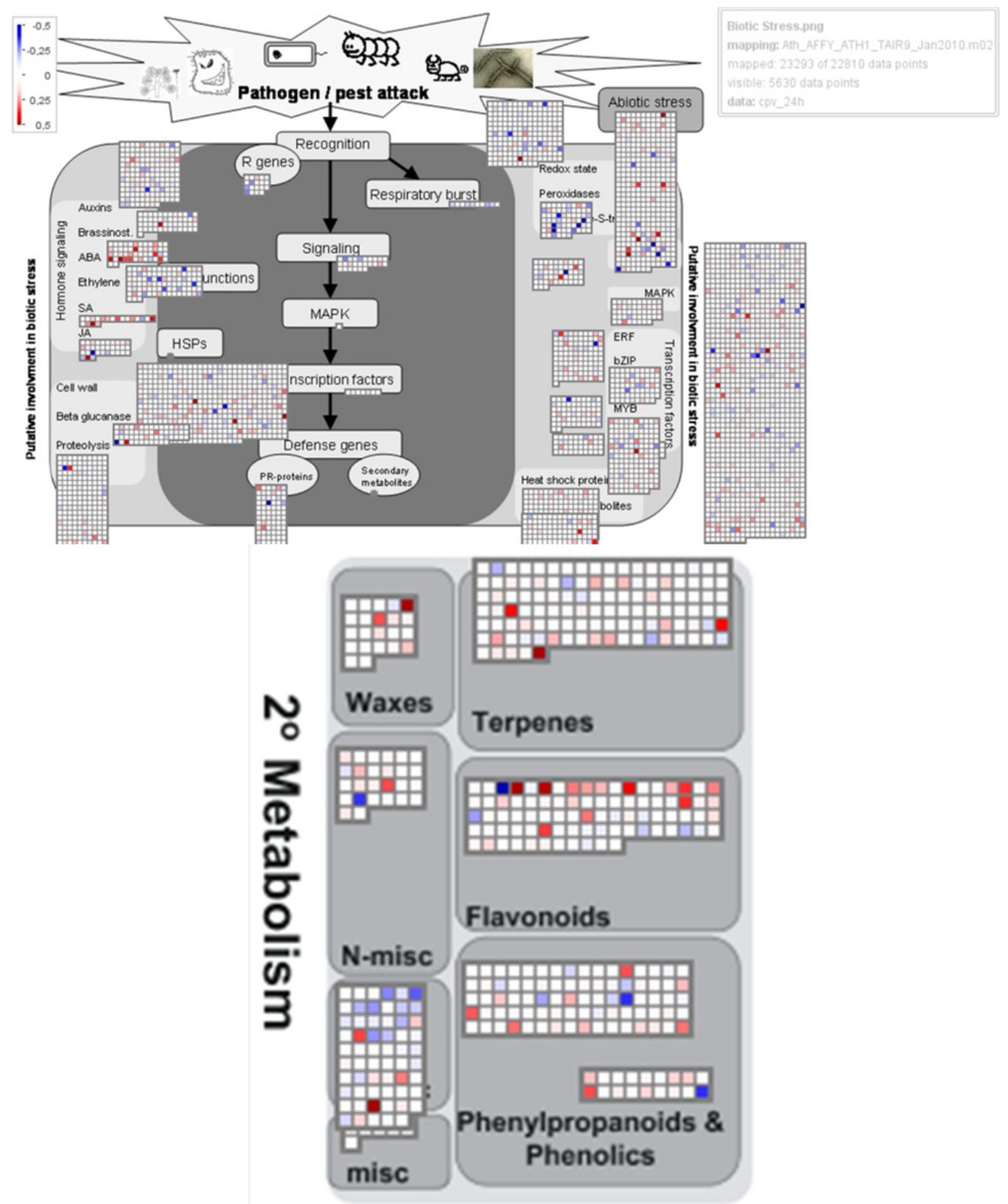

Fig. 3. Microarray data of VAL-P01 and VAL-P02 (averaged changes in transcript level from two biological replicates) were analysed using the MapMan software. The output of the software is shown, only for VAL-P01, with the genes involved in each metabolic step represented by a small square. A blue square (and blue shades) indicates a gene whose transcript level decreased following the treatment. A red square (and red shades) indicates a gene whose transcript level increased following the treatment. 


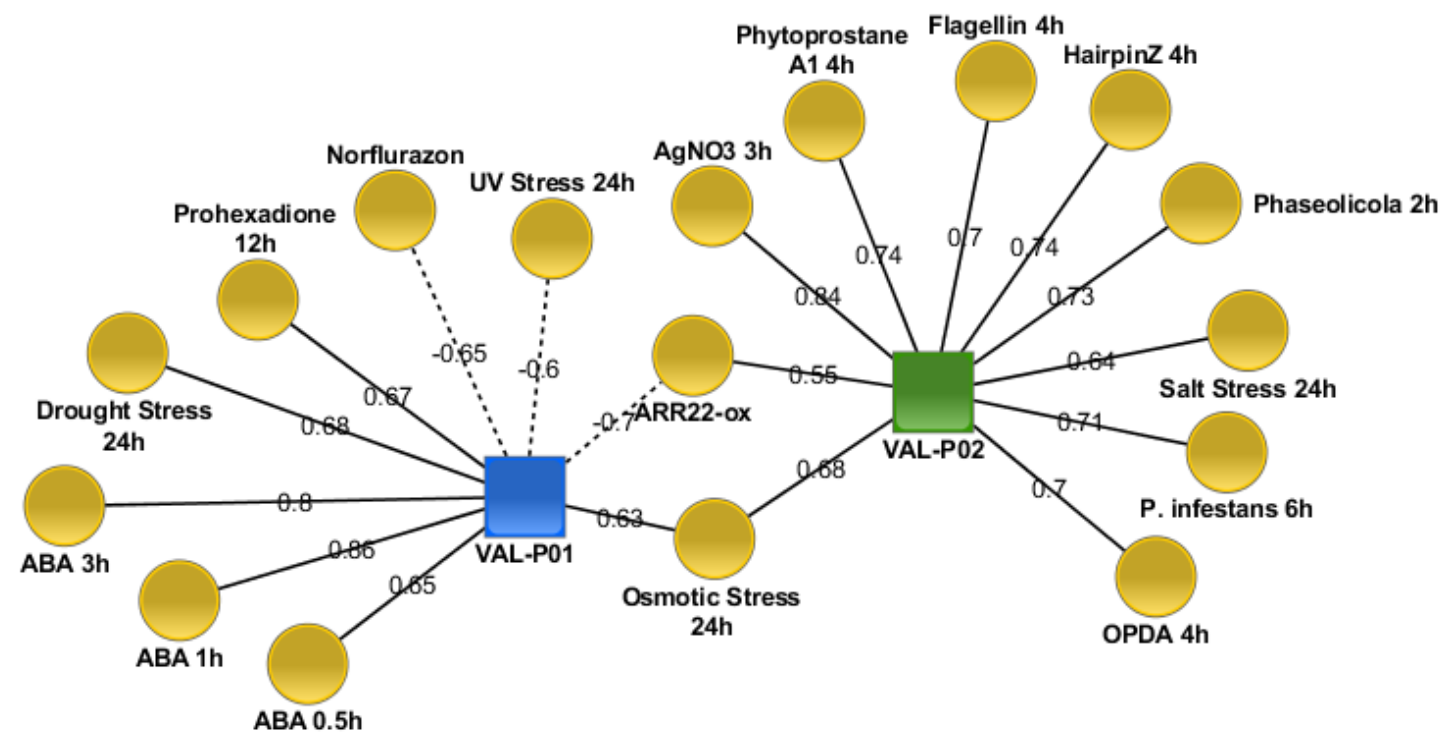

Fig. 4. AtCAST-inferred cytoscape network representations of the 10 public experiments most correlated to VAL-P01 and VAL-P02. Dashed lines represent negative correlations. Identical treatments on different tissues are merged into unique network nodes.

A

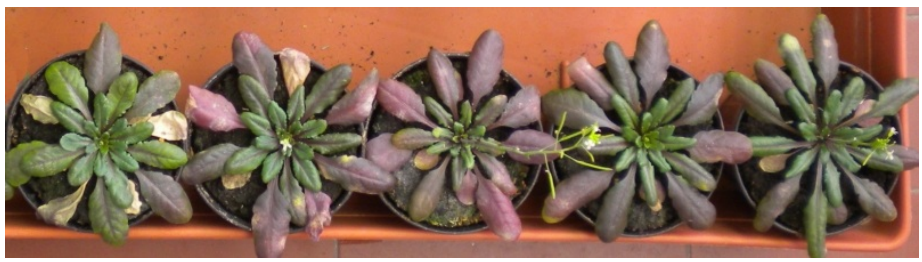

B

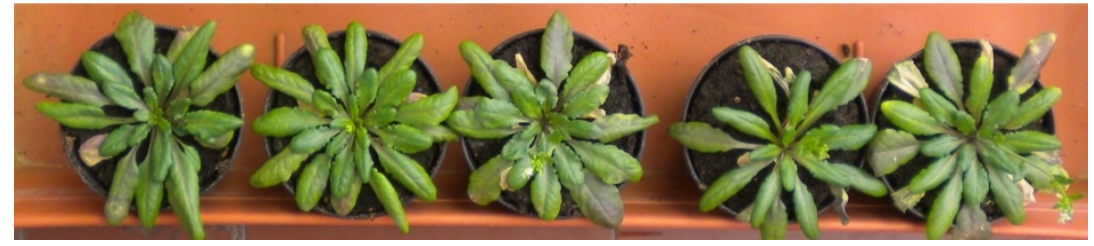

Fig. 5. Effect of drought stress on Arabidopsis plants deprived of water for 10 days. The plants that were previously treated with VAL-P01 (B) display a much better tolerance in comparison with the control plants (A). 